\title{
The earliest site of atrial activation in patients with isomeric appendages
}

Hideki Uemura, Toshikatsu Yagihara, Yasunaru Kawashima, Kenji Okada, Robert H Anderson

\begin{abstract}
Background-The sinus node is known to be duplicated in hearts with bilateral right appendages, but its site is uncertain when both appendages are of morphologically left pattern.
\end{abstract}

Objective-To determine the earliest site of activation of the atria, and to assess this site of activation relative to the anticipated location of the sinus node in patients with isomeric atrial appendages. Study design-Electrophysiological recordings by epicardial mapping during operations through a median sternotomy. Patients-Since 1987, 44 consecutive patients with isomeric right appendages and 23 with isomeric left appendages.

Results-In $77 \%$ of the patients with isomeric right appendages, the site of earliest activation was superiorly located at the junction of one or other atrium and a superior caval vein; in other words, in the anticipated site of a sinus node. In contrast, an inferior site of earliest activation at the junction of an atrium with an hepatic vein was most common in patients with isomeric left appendages $(56 \%)$. The site of earliest activation was not related to the veno-atrial junctions in six patients with isomeric right appendages (14\%), nor in five with isomeric left appendages (22\%). Moreover, in six patients with isomeric right appendages $(13 \%)$, and three with isomeric left appendages (13\%), additional sites of earliest activation were observed when the dominant site was suppressed. The locations of the earliest activation observed by epicardial mapping did not always accord with those expected from the preoperative electrophysiological examination, nor did they always match the anticipated site of the sinus node as documented by previous histological investigations.

National Center, Suita, Osaka, Japan

H Uemura

T Yagihara

K Okada

Y Kawashima

National Heart and

Lung Institute,

London

H Uemura

R H Anderson

Correspondence to Prof R H Anderson Department of Paediatrics, National Heart and Lung Institute, Dovehouse Street, London SW3 $6 \mathrm{LY}$.

Accepted for publication 8 March 1995

A biventricular repair, ${ }^{12}$ or a right heart bypass operation, ${ }^{3-5}$ is increasingly employed in patients with isomeric atrial appendages thmia can occasionally be lethal after such surgery.$^{67}$ Indeed, in our series of 91 patients with isomeric atrial appendages and undergoing anatomical biventricular repair or right heart bypass at the National Cardiovascular Centre in Osaka, supraventricular tachycardia or atrioventricular nodal rhythm was thought to have deleterious effects in six patients dying within 30 days of the operation $(50 \%$ of 12 overall). Rhythm problems were also suspected as a probable cause of late sudden death in two patients (out of three sudden deaths occurring in the long term). If such arrhythmias are associated with structural abnormalities of, or surgical damage to, the specialised conduction tissues, their incidence postoperatively could be reduced by precise knowledge of the morphological and functional arrangements of the atrial pacemakers. Our present study, therefore, was designed to identify the earliest sites of atrial activation by means of electrophysiological examinations during surgical procedures.

\section{Methods}

Epicardial mapping was performed in 44 patients with isomerism of morphologically right appendages, and in 23 with isomerism of left appendages, the patients undergoing either palliative or definitive surgery at the National Cardiovascular Centre in Osaka, Japan. The major surgical procedures are shown in table 1. The electrophysiological recordings were performed after median sternotomy and before any surgical manoeuvres, using the HPM-7100 mapping

Table 1 Surgical procedures performed. Values are numbers of patients

\begin{tabular}{|c|c|c|}
\hline & $\begin{array}{l}\text { Isomeric } \\
\text { right } \\
\text { appendages }\end{array}$ & $\begin{array}{l}\text { Isomeric } \\
\text { left } \\
\text { appendages }\end{array}$ \\
\hline \multicolumn{3}{|l|}{ Definitive surgery } \\
\hline \multicolumn{3}{|l|}{ Biventricular repair } \\
\hline \multicolumn{3}{|l|}{ Intra-atrial and intraventricular } \\
\hline rerouting & 0 & 4 \\
\hline Intra-atrial rerouting & 0 & 4 \\
\hline \multicolumn{3}{|l|}{ AVSD repair and intraventricular } \\
\hline rerouting & 0 & 3 \\
\hline AVSD repair & 0 & 4 \\
\hline Atrial septation & 0 & 2 \\
\hline \multicolumn{3}{|l|}{ Functional repair } \\
\hline TCPC and TAPVC repair & 7 & 0 \\
\hline TCPC without other options & 23 & 2 \\
\hline \multicolumn{3}{|l|}{ Palliative surgery } \\
\hline \multicolumn{3}{|l|}{ BDG, TAPVC repair and plasty } \\
\hline BDG and plasty of AV valve & 5 & 1 \\
\hline BDG without other operations & 2 & 2 \\
\hline TAPVC repair & 6 & 0 \\
\hline Surgery to AV valve & 0 & 1 \\
\hline
\end{tabular}
(visceral heterotaxy). Supraventricular arrhy- 
Figure 1 (A) The cardtype 24-point electrodes. The white board is made of flexible plastics, and can be fitted to the curved surfaces fitted to the curved surfaces
of the heart. (B) A typical demonstration of the earliest site of activation recorded by the epicardial atrial mapping in a patient with isomerism of the left appendages.
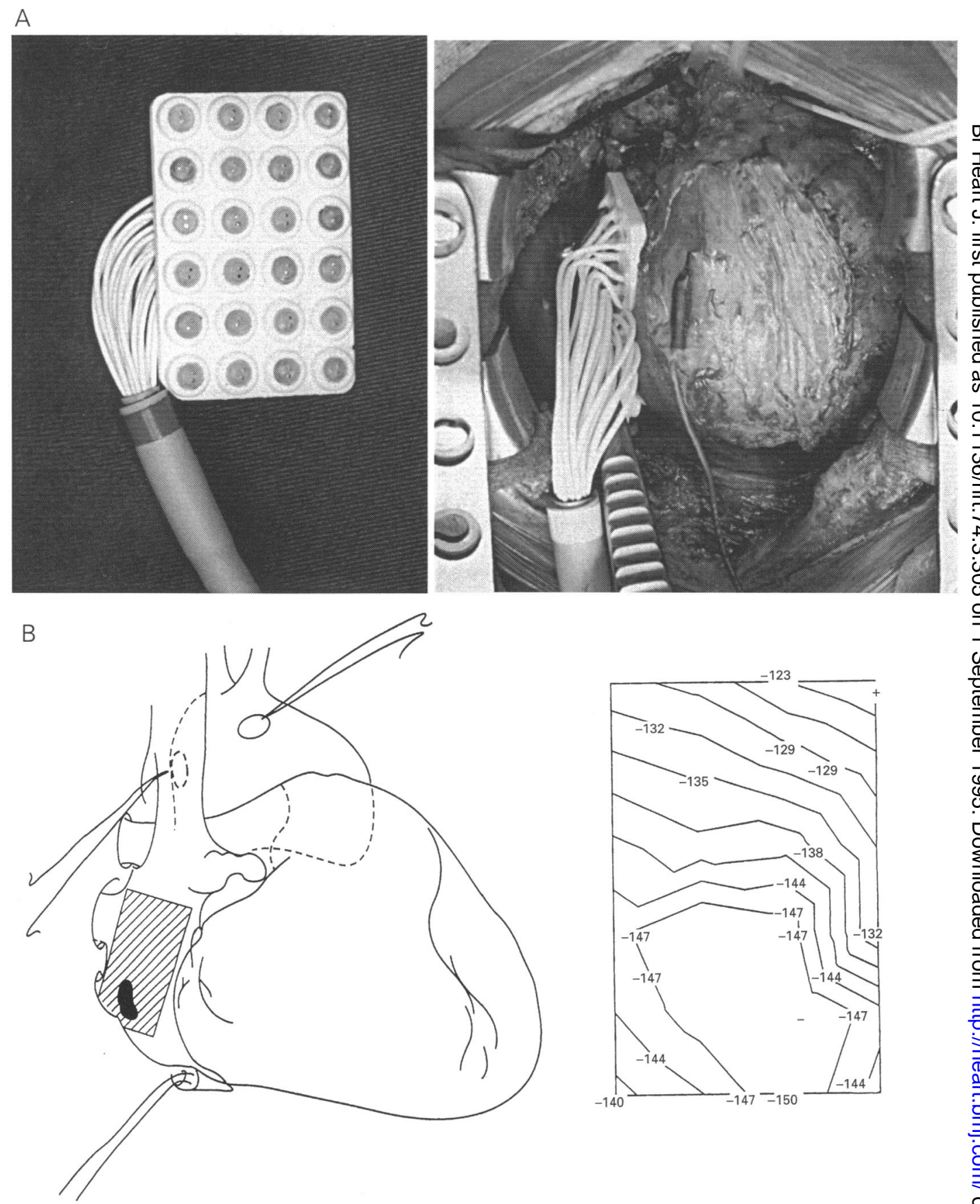

computer (Nihon Kohden) together with a card-type device which had 24-point electrodes capable of simultaneous recording (fig 1A). The site of earliest activation of the atria (fig 1B) was first identified two or three times in stable intrinsic rhythm, and then once or twice following overdrive atrial pacing, the latter manoeuvre showing the site with the shortest sinus node recovery time. In addition to these recordings, we attempted to reveal subdominant or additional sites of earliest activation, either by suppressing the initially recorded site using cold water or, if possible, after induction of supraventricular tachycardia. The demonstrated sites of earliest activation were compared with the locations of the sinus nodes assumed from the $P$ wave vector of preoperative standard 12-lead electrocardiograms, or as anticipated from the result of body surface mapping.

\section{Results}

The site of earliest activation at a stable rhythm was shown consistently throughout two or three recordings in each instance. The site of earliest activation following overdrive atrial pacing always accorded with that found in stable rhythm. In addition, this location was consistent with the $P$ wave vector simultaneously derived from electrocardiographic leads placed on extremities during the recordings.

Marked variation was found in the dominant site of earliest activation in terms of the patterns of systemic venous connections to the atrial chambers (figs 2 and 3). In 34 of 44 patients with isomeric right appendages, the earliest activation was located at the junction of one or other atrium and a superior caval vein (table 2). In another four patients with isomerism of the right appendages, the earliest 
Figure 2 The earliest site of activation in the group of hearts with isomeric right appendages in relation to the connections between the systemic veins and the atria.

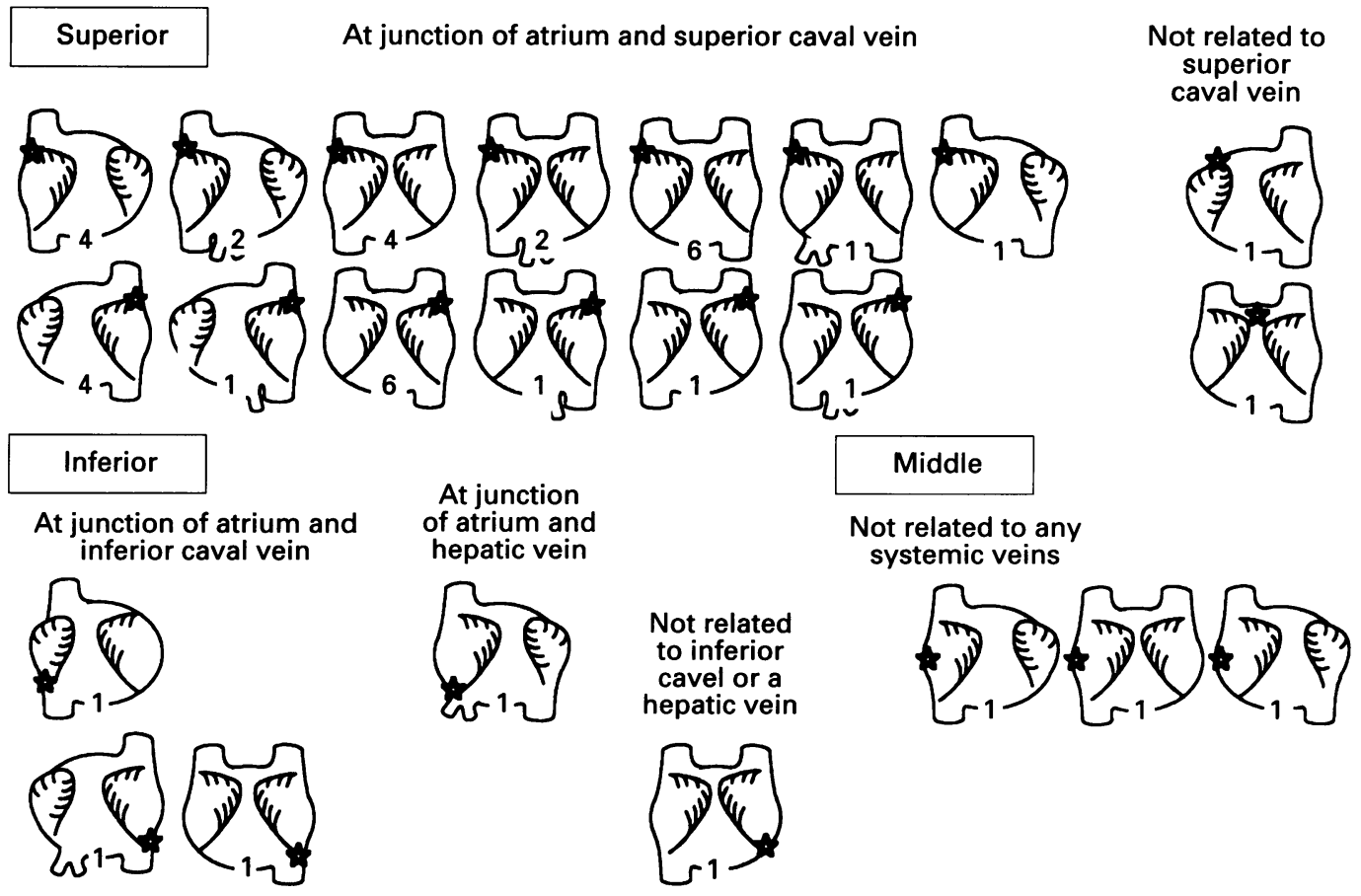

Figure 3 The earliest site of activation in hearts with isomeric left appendages and patterns of systemic venous drainage.
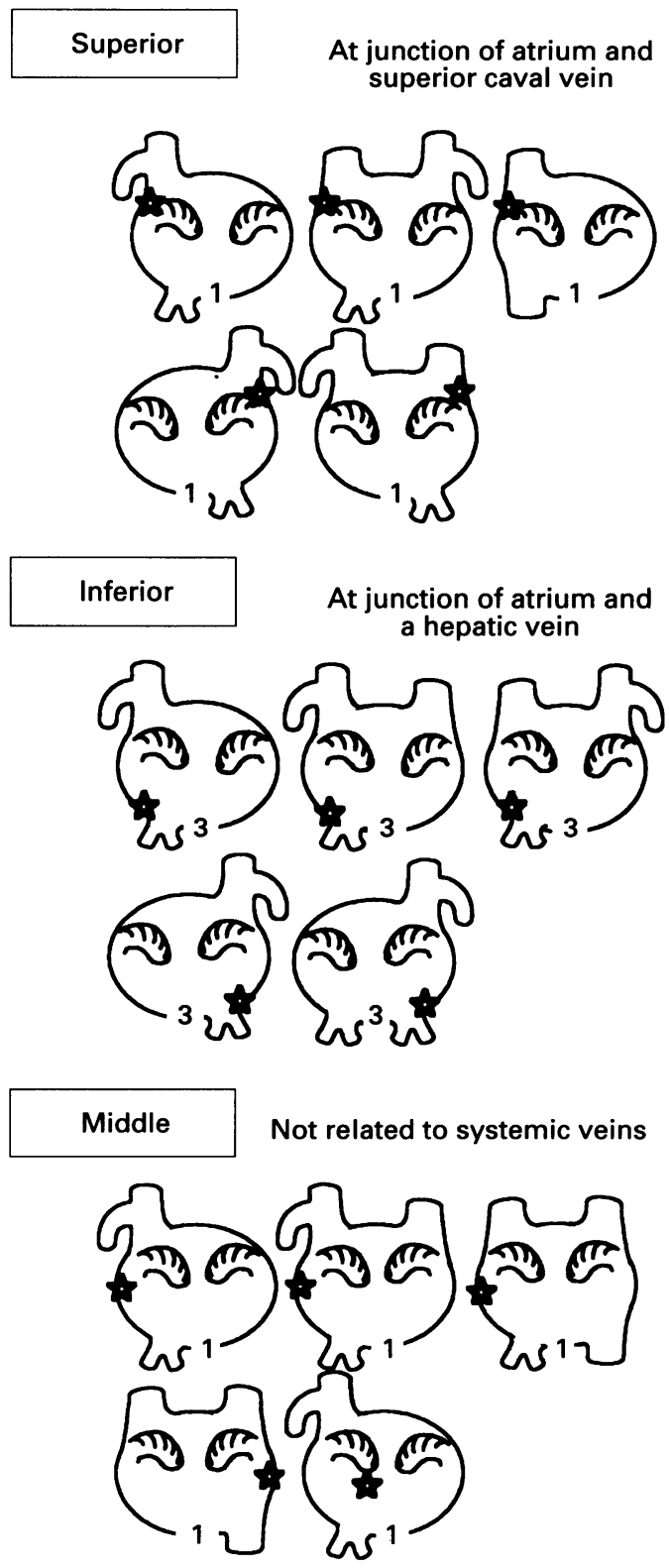

activation was at the junction of an atrium and either an inferior caval or a hepatic vein. The site of earliest activation was not related to either a caval vein or a hepatic vein in six patients, these being located superiorly in two, at mid-atrial level in three, and inferiorly in one (fig 2). A superior location for earliest activation at the junction of an atrium and a superior caval vein was much less frequent in the setting of isomeric left appendages (table 2 ). Instead, the commonest site was at the junction of one or other atrium and a hepatic vein (fig 3). Sites unrelated to the veno-atrial junctions were seen in five patients.

An additional site of earliest activation could be induced in six patients with right isomerism (14\%), and in three with left isomerism (13\%). These additional sites were related to the superior caval vein (six sites), the inferior caval vein (two sites), or a hepatic vein (one site), with one being unrelated to the veno-atrial junctions (fig 4).

The sites of the sinus node as assumed from the $P$ wave vector determined at preoperative examinations were discordant in a relatively high proportion of cases with the sites of earliest activation, as demonstrated by epicardial mapping (table 3 ).

Table 2 Overall sites of earliest activation

\begin{tabular}{|c|c|c|}
\hline $\begin{array}{l}\text { Function of } \\
\text { SCV to atrium }\end{array}$ & $\begin{array}{l}\text { Function of ICV } \\
\text { or } H V \text { to atrium }\end{array}$ & $\begin{array}{l}\text { Not related to } \\
\text { SCV, ICV, } \\
\text { or } H V\end{array}$ \\
\hline $\begin{array}{l}\text { Isomeric right appendages } \\
\text { Right side } 45 \% \\
\text { Left side } \quad 32 \%\end{array}$ & $\begin{array}{l}5 \% \\
4 \%\end{array}$ & $14 \%$ \\
\hline $\begin{array}{l}\text { Isomeric left appendages } \\
\text { Right side } 13 \% \\
\text { Left side } 9 \%\end{array}$ & $\begin{array}{l}39 \% \\
17 \%\end{array}$ & $22 \%$ \\
\hline
\end{tabular}

SCV, superior caval vein; ICV, inferior caval vein; HV, hepatic 
Isomeric right appendages

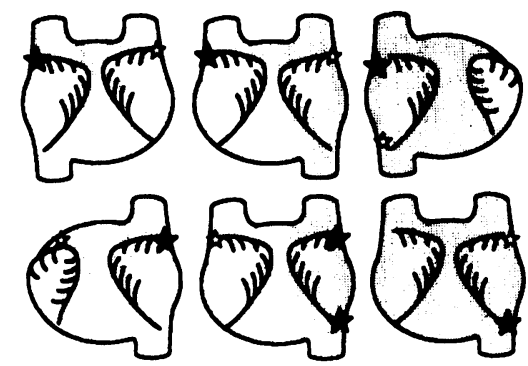

Isomeric left appendages

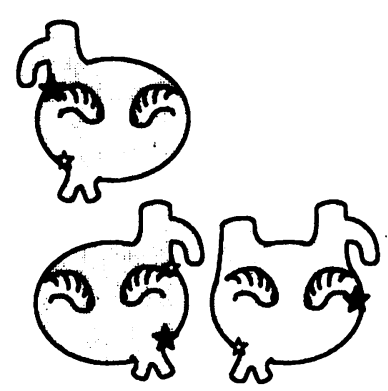

$\star$, additional site of earliest activation , initially recorded site at stable rhythm

Figure 4 Induced additional sites of earliest activation.

Table 3 Comparison with preoperative examination

\begin{tabular}{|c|c|c|c|c|}
\hline \multirow{2}{*}{$\begin{array}{l}\text { Sites of the sinus } \\
\text { node assumed from } \\
P \text { wave vector }\end{array}$} & \multicolumn{4}{|c|}{$\begin{array}{l}\text { The site of earliest activation } \\
\text { by epicardial mapping }\end{array}$} \\
\hline & \multicolumn{2}{|c|}{ Concordant } & \multicolumn{2}{|c|}{ Discordant } \\
\hline \multicolumn{5}{|c|}{ By usual 12-lead electrocardiogram } \\
\hline Multaple ( & 10 & $\begin{array}{l}43 \\
(64 \%)\end{array}$ & 9 & $\begin{array}{l}24 \\
(36 \%)\end{array}$ \\
\hline Single $(n=43)$ & 28 & & 15 & \\
\hline \multirow[t]{2}{*}{$\begin{array}{l}\text { By body surface mapping } \\
\text { Multiple }(n=3)\end{array}$} & 1 & & 2 & \\
\hline & & $\begin{array}{l}10 \\
(46 \%)\end{array}$ & & $\begin{array}{l}19 \\
(54 \%)\end{array}$ \\
\hline Single $(\mathrm{n}=32)$ & 15 & & 17 & \\
\hline
\end{tabular}

\section{Discussion}

In the normal heart, the sinus node is known to be located subepicardially within the terminal groove at the junction of the superior caval vein and the morphologically right atrium..$^{8-10}$ The terminal groove (sulcus terminalis) is a prominent and well recognised landmark, and the course of the sinus nodal artery, if visible, is helpful in confirming the nodal location. In congenitally malformed hearts with the usual atrial arrangement, and with the usual connections between the systemic veins and the right atrium, the sinus node remains at this normal location, while the node is mirror imaged in those with so called "situs inversus". This knowledge is crucial for those performing heart surgery, particularly in such procedures as the so called "Maze" operation for atrial arrhythmias, ${ }^{11}$ the Mustard or Senning procedures for intra-atrial switching, and intra-atrial manoeuvres for repair of partially anomalous pulmonary venous connection when the upper pulmonary vein is connected to the superior caval vein.

In hearts with an isomeric arrangement of the atrial appendages, however, the venoatrial connections are almost always abnormal. ${ }^{12}{ }^{13}$ In consequence, the location of the sinus node is very likely to be abnormally located. Furthermore, when the appendages are isomeric, the landmarks to the precise site of the node are either duplicated or equivocal. ${ }^{14}$ Thus, as has been established by morphological and histological studies, the sinus node is duplicated in hearts with isomerism of morphologically right atrial appendages, being located bilaterally at the junction between the superior caval veins and the atria. ${ }^{12} 1516$ In contrast, in the group of hearts with isomeric left appendages, the sinus node is known to be frequently hypoplastic, or else to be absent as a histologically recognised structure.

The functional location of the atrial pacemaker can be demonstrated by data derived from electrophysiological studies. ${ }^{15} 17$ Theoretically, the anatomical location of the sinus node should accord with the site of earliest activation during sinus rhythm. It was this information which helped Lewis and his colleagues $^{18}$ to confirm the role of the histologically demonstrated sinus node ${ }^{19}$ as the cardiac pacemaker. ${ }^{20}$ Indeed, in a large series of our patients with the usual atrial arrangement or its mirror image, we found that the site of earliest atrial activation was always concordant with the anatomically expected location of the sinus node, as well as with its anticipated location as determined by the $P$ wave vector derived from the usual electrocardiograms. The term "sinus node", nonetheless, is best reserved for the structure demonstrated morphologically. The locations recorded in our present study are more properly described, therefore, as the sites of earliest activation of the atria. As shown, some hearts with right isomerism had sites of earliest activation which did not accord with the locations of the sinus node as demonstrated by previous histological studies. It is clear that in these patients the site of earliest activation does not coincide with the anatomical location of the node. As yet, we have no explanation for these discrepancies.

The relatively low capability of inducing additional sites of earliest activation was also surprising. We had expected to be able to induce such additional sites of activation much more frequently in those patients with isomeric right appendages. This low incidence could well be due to the circumstances of recording during surgical operations. Deep anaesthesia for surgery reduces the concentration of catecholamines within the blood and, eventually, we presume that the activity or susceptibility of excitation will be decreased within the sinus nodes. Furthermore, in such circumstances, the dominant pacemaker can be one of the two sinus nodes bilaterally located, with the other node being the one dominating the cardiac rhythm at rest or exercise before the operation. In this respect, it is noteworthy that the discrepancies were frequently noted between the anticipated location of the sinus node from the $P$ wave vector derived from preoperative non-invasive examinations and the site of earliest activation recorded by epicardial mapping. The question these findings raises is whether the surgeon could, or should, ablate the subdominant pacemakers masked in waking condition when the locations of such pacemakers are recorded as the sites of earliest activation during the operation. If carried out, such procedures may leave only one efficient sinus node, thus 
minimising the potential for postoperative tachyarrhythmias, particularly in patients with isomerism of the right appendages.

In this series of patients, nonetheless, we considered it prudent, and made it a rule, scrupulously to avoid any damage to the site of earliest activation at both the initial atriotomy and during subsequent intra-atrial manoeuvres. We also avoided the areas of potential nodal candidates as revealed by previous histological studies. In patients with isomeric right appendages, damaging both the sinus nodes - together with the earliest site of atrial activation-would induce an overall insufficiency of sinus nodal function. As yet, we have no proof as to which location is the most efficient, and should be left as an atrial pacemaker. In those with isomerism of the left appendages, in contrast, the sites of earliest activation recorded electrophysiologically are likely to be of more practical value in preserving regular atrial rhythm after surgery, since there is no well established location for a well formed sinus node in this setting. In other words, loss of regular atrial rhythm might well be produced by damaging the site of earliest activation adjacent to the junction between a hepatic vein and the atrium. Such unwanted injuries can be produced not only by atrial incisions or intra-atrial suture lines, but also by cannulation into the hepatic vein for establishment of cardiopulmonary bypass. After avoiding these areas in our patients, we at least succeeded in achieving no postoperative evidence of disappearance of the $P$ wave in any patient.

The location of the sinus node within the high pressure pathway in the setting of the Fontan circulation may also have deleterious potential for inducing atrial arrhythmias. Our preference, therefore, has been to place the atrial wall containing the pacemakers within the low pressured chamber. ${ }^{21}$ The correlation between these possible surgical traumas or mechanical influences and the occurrence of postoperative atrial arrhythmia remains unclear. Further investigations are undoubtedly necessary. Since our present study was designed in our series of consecutive patients, we have no control group in which the patients underwent surgical procedures without performing epicardial mapping. Moreover, postoperative evaluations such as a precise study on sinus node recovery time and exercise loading tests would be necessary to prove the absence of sinus nodal dysfunction.

In all these respects, if the epicardial recordings had been concordant with the preoperatively anticipated locations in nearly all our patients, it would have been unnecessary to perform epicardial mapping in every case. This is of some consequence, since the manoeuvre takes about half an hour to complete and thus prolongs the total duration of the operation. Our technique of epicardial mapping, nonetheless, is an eminently feasible method for estimating the locations of earliest atrial activation, its information supplementing the findings already established. To the best of our knowledge, such epicardial mapping, by which it was attempted to improve surgical results, has not been reported previously.

In summary, our epicardial mapping revealed considerable diversity in the site of the earliest activation of the atria in hearts with isomeric atrial appendages. A site at the junction of an atrium and a superior caval vein was most frequent in hearts with isomerism of the right appendages, while an inferior site of activation at the junction of an atrium and a hepatic vein was relatively common in those with isomerism of the left appendages. Additional sites of earliest activation could be detected in some patients. The information provided by this technique might contribute in the future to better surgical outcomes.

1 Kawashima Y, Matsuda H, Naito Y, Yagihara T, Kadoba $\mathrm{K}$, Matsuki $\mathrm{O}$. Biventricular repair of cardiac isomerism with common atrioventricular canal with the aid of an endocardial cushion prosthesis. $\mathcal{F}$ Thorac Cardiovasc Surg 1993;106:248-54.

2 Pacifico AD, Ricchi A, Bargeron LMJ, Colvin EC, Kirklin JW, Kirklin JK. Corrective repair of complete atrioventricular canal defects and major associated cardiac anomalies. Ann Thorac Surg 1988;46:645-51.

3 Stein JI, Smallhorn JF, Coles JG, Williams WG, Trusler $\mathrm{GA}$, Freedom RM. Common atrioventricular valve guarding double inlet atrioventricular connexion: natural guarding double inlet atrioventricular connexion: natural
history and surgical results in 76 cases. Int $\mathcal{F}$ Cardiol history and surgi

4 Humes RA, Feidt RH, Porter CJ, Julsrud PR, Puga FJ, Danielson GK. The modified Fontan operation for asplenia and polysplenia syndrome. F Thorac Cardiovas Surg 1988;96:212-8.

5 Kawashima Y, Kitamura S, Matsuda H, Shimazaki Y, Nakano S, Hirose $H$. Total cavopulmonary shunt operation in complex cardiac anomalies: a new operation $\boldsymbol{f}$ Thorac Cardiovasc Surg 1984;87:74-81.

6 Matsuda $H$, Kawashima $Y$, Kishimoto $H$, Hirose $H$ Nakano S, Kato $\mathrm{H}$, et al. Problems in the modified Fontan operation for univentricular heart of the right ventricular type. Circulation 1987;76 (suppl III): III45-52.

7 Gelatt M, Hamilton RM, McCrindle BW, Gow RM, Williams WG, Freedom RM. Risk factors for atrial tachydysthythmias after Fontan operation. $\mathcal{f} \mathrm{Am}$ Coll $\underset{\text { Cardiol 1994;43rd Annual Scientific }}{f}$ Session [abstract]:104A.

8 Anderson RH, Becker AE. Cardiac anatomy: the conduction system. In: Anderson RH, Becker AE, eds. The heart. tion system. In: Anderson RH, Becker AE, eds. The hean

9 Wilcox BR, Anderson RH. Surgical anatomy of the chambers of the heart and great arteries: morphologically right atrium. In: Wilcox BR, Anderson RH, eds. Surgical anatomy of the heart, 2nd ed. London: Gower Medical Publishing, 1992;2:6-12.

10 Anderson RH, Ho SY. The morphologic substrates for pediatric arrhythmias. Cardiol Young 1991;1:159-76.

$11 \mathrm{Cox} \mathrm{JL}$. The surgical treatment of atrial fibrillation. Surgical technique. $\mathcal{F}$ Thorac Cardiovasc Surg 1991;101: 584-92.

12 Van Mierop LHS, Wiglesworth FW. Isomerism of the cardiac atria in the asplenia syndrome. Lab Invest 1962; diac atria in th

13 Kirklin JW, Barratt-Boyes BG. Atrial isomerism. In: Kirklin JW, Barratt-Boyes BG, eds. Cardiac surgery, 2nd ed, vol 2. New York: Churchill Livingstone, 1993: ed, vol $1585-96$

14 Anderson RH, Becker AE. Congenital malformations: anomalies of atrial arrangement. In: Anderson $\mathrm{RH}$ Becker AE, eds. The heart. London: Gower Medical Publishing, 1992;6:1-6.

15 Dickinson DF, Wilkinson JL, Anderson KR, Smith A, Ho $S Y$, Anderson RH. The cardiac conduction system in situs ambiguous. Circulation 1979;59:879-85.

16 Ho SY, Cook A, Anderson RH, Allan LD, Fagg N. Isomerism of the atrial appendages in the fetus. Pediatr Pathol 1991;11:589-608.

17 Momma K, Takao A, Shibata T. Characteristics and natural history of abnormal atrial rhythms in left isomerism. Am f Cardiol 1990;65:231-6.

18 Lewis T, Oppenheimer BS, Oppenheimer A. Site of origin of the mammalian heart beat: the pacemaker in the dog. Heart 1910;2:147-69.

19 Keith A, Flack M. The form and nature of the muscular connections between the primary divisions of the vertebrate heart. $\mathcal{F}$ Anat Physiol 1907;41:172-89.

20 Eyster JAE, Meek WJ. Experiments on the origin and propagation of the impulse in the heart: point of primary negativity in the mammalian heart and the spread of negativity in the mammalian heart and the spread

21 Yagihara $T$, Kishimoto $H$, Isobe $F$, Yamamoto $F$, Nishigaki $\mathrm{K}$, Uemura $\mathrm{H}$, et al. Indication and result of right heart bypass operation. $\mathfrak{f p n}_{p} \mathcal{f}$ Cardiovasc Surg 1991;20:1389-92 (in Japanese). 